\title{
La huella urbana de la muralla de Osuna. Estudio del plano y de las fuentes documentales y arqueológicas ${ }^{1}$
}

\author{
The urban footprint of Osuna wall. Study of plan and of documentary and \\ archaeological sources
}

Mercedes Díaz Garrido²

Recibido: 15/06/21

Aceptado: 14/09/21

Publicado: 10/02/2022

\begin{abstract}
RESUMEN
De lo que fuera la muralla medieval de la ciudad de Osuna, solo permanecen en pie en la actualidad la torre del Agua y algunos restos aislados, como los que dan nombre al cerro de los Paredones o los recientemente excavados en la calle Caldenegros. Nuestro objetivo es proponer su posible trazado, la posición de las puertas y de los elementos singulares próximos, así como el dibujo del plano aproximado del entorno de las mismas. El análisis se refiere a la situación del conjunto en el siglo XVI, momento clave en el urbanismo de la ciudad, al cual remite la documentación manejada.

Para ello, nos basamos en el estudio conjunto del plano y de las fuentes documentales y arqueológicas. El análisis del plano persigue identificar la huella de la muralla en la trama urbana consolidada. Esto hace que el trabajo se ciña a la parte del circuito que discurre por lo que hoy permanece como tal, aproximadamente su mitad noroeste.
\end{abstract}

Palabras clave: análisis urbano, historia urbana, muralla medieval, Osuna.

El trabajo forma parte de otro más general en el que se aborda el urbanismo de la ciudad de Osuna en el siglo XVI, etapa fundamental de su conformación urbana actual, en la que esta se convierte en ciudad nobiliaria con los Téllez Girón, condes de Ureña. Un avance se presentó como comunicación a el congreso (ver nota 1) y ha sido continuado posteriormente siendo objeto de un mayor desarrollo, que esperamos poder ver publicado pronto con el título

\begin{abstract}
Of what was once the medieval wall of the city of Osuna, only the Torre del Agua and some isolated remains remain standing today, such as those that give name to the "Cerro de los Paredones" or those recently excavated in Calle Caldenegros. Our objective is to propose their possible layout, the position of the gates and of the nearby singular elements, as well as the drawing of the approximate plan of their surroundings. The analysis refers to the situation of the complex in the $16^{\text {th }}$ century, a key moment in city urbanism, to which the documentation refers.

For that purpose, we have based our work on the joint study of the plan and the documentary and archaeological sources. The analysis of the plan aims to identify the imprint of the wall on the consolidated urban fabric. This means that the work is limited to the part of the circuit that runs along what remains as such today, that is, approximately its north-western half.
\end{abstract}

Keywords: urban analysis, urban history, medieval wall, Osuna.

"Osuna en el XVI. Síntesis de una transformación urbana". En él se recogen los resultados aquí alcanzados, al tiempo que los sitúa en su contexto espacial y temporal.

Como se anuncia en el título, nos proponemos analizar la muralla medieval de Osuna a través de su huella en la trama urbana, ya que los restos conservados son escasos, tanto los emergentes como los documentados por la

\footnotetext{
1. El trabajo se desarrolla como continuidad del Proyecto I+D "Diego de Riaño, Diego de Siloé y la transición del Gótico al Renacimiento en España" (HAR 2016-76371-P, Ministerio de Economía y Competitividad). Investigadores principales: Juan Clemente Rodríguez Estévez y Antonio Luis Ampliato Briones.

Una primera aproximación a la ciudad de Osuna en conjunto se presentó como comunicación en el congreso celebrado hacia el cierre del proyecto y será publicada en el libro de actas (DÍAZ, en prensa).

2. Arquitecta. Profesora Contratada Doctora. E.T.S. de Arquitectura. Universidad de Sevilla.
}

Cómo citar: Díaz Garrido, M. (2022): La huella urbana de la muralla de Osuna. Estudio del plano y de las fuentes documentales y arqueológicas. Arqueología Y Territorio Medieval, 29. e6433. https://doi.org/10.17561/aytm.v29.6433 
arqueología. El objeto no es por tanto su conocimiento material, cronológico o constructivo, sino su desarrollo espacial en el plano, como parte integrante del conjunto urbano en un momento dado y como elemento principal en el proceso orgánico de construcción de la ciudad.

Nuestro objetivo es aportar nuevos argumentos sobre su trazado, así como sobre la situación de las puertas, elementos singulares y viario asociado a las mismas, atendiendo a la forma del plano en que se inserta y teniendo en cuenta topografía, recorridos y parcelario, con el apoyo fundamental de las fuentes documentales y arqueológicas.

El método empleado, desarrollado en una publicación anterior (DÍAZ, 2017), supone el acercamiento a la ciudad como construcción histórica y la lectura de su proceso de formación a través del análisis de la forma urbana reflejada en el plano. Lectura que se basa en principios morfológicos y estratigráficos, con el análisis urbano de los arquitectos y la arqueología de la arquitectura de los arqueólogos como principales referentes teóricos.

El trabajo se circunscribe a la parte del recorrido que discurre por las manzanas cuyo parcelario ha permanecido como parte consolidada de la ciudad. Es decir, las delimitadas por las actuales calles Luis de Molina y San Antón al norte, y Asistente Arjona y de la Torre al oeste. En el ángulo noroeste, en contacto con la plaza, se hace difícil rastrear la muralla en el plano, ya que la transformación urbana ha sido muy intensa. Sin embargo, en este sector abundan los documentos con referencias a elementos de la estructura urbana, en cuyo traslado al plano nos hemos basado. Documentos que conocemos gracias a la valiosa recopilación realizada por Francisco Ledesma (LEDESMA, 2003).

\section{ANTECEDENTES}

El trabajo de mayor alcance realizado sobre la muralla de Osuna es el ya citado de Francisco Ledesma, titulado "Las murallas de Osuna"
(2003). En él se trata de recomponer el sistema defensivo de la ciudad, a través de un estudio que aborda distintas cuestiones, desde la consideración del contexto histórico o de las fuentes gráficas y bibliográficas, al análisis de los vestigios conservados y de la documentación de archivo, entre otros.

Sobre su origen no se llega a una conclusión precisa, apuntando a la profunda remodelación, si no total reconstrucción y redefinición del recinto en época almohade. Este sería objeto de una importante intervención en el siglo XIV, momento en que se construyen las bóvedas interiores de la torre del Agua y se realiza el revestimiento de sillares que presentan al exterior los restos de muralla conservados.

Respecto al trazado del recinto y a la ubicación de las puertas, se realiza una propuesta de conjunto que se ha tenido en cuenta en este trabajo y con la cual coincidimos en parte. Básicamente, para el sector que aquí analizamos, las diferencias principales están en la localización de la puerta Nueva, en la localización y esquema de la puerta del Agua, y en el trazado propuesto para el tramo al sur de esta última y su relación con la torre y con la desaparecida iglesia de San Juan.

Otro aspecto que el autor recoge son las referencias documentales a los espacios urbanos asociados a la muralla, con el objeto de ofrecer una cierta imagen de los mismos. Sobre esta base hemos querido también avanzar, llegando a dibujar de forma más concreta el plano en el entorno de ambas puertas: en el entorno de la puerta Nueva, con la situación inicial de cierre del arrabal y, en el entorno de la puerta del Agua, con la situación previa a la reforma que supuso, a finales del siglo, la apertura de la "nueva calle", así como la posible ubicación de la iglesia de San Antón.

En cuanto al conocimiento material directo, la escasez de vestigios hace que este sea limitado. Los estudios arqueológicos consisten en hallazgos puntuales relacionados con actividades de urgencia. Además de esto, se vienen realizando 
actuaciones por parte del ayuntamiento que han sacado recientemente a la luz importantes restos en la calle Caldenegros, cuyos resultados no han sido aún publicados. A continuación, hacemos referencia a los mismos en orden cronológico, comenzando por una referencia a los lienzos de muro conocidos como "Paredones".

Como Paredones se conocen los restos de lo que habría sido la pared exterior del palacio-fortaleza, integrante del recinto defensivo en su parte más elevada hacia el este. Consisten en un lienzo de mayor longitud y dos tramos cortos alineados con este, construidos en tapial con restos de un revestimiento de sillares (LEDESMA, 2003: 199).

"Intervención Arqueológica de Urgencia en la Torre del Agua" (SALAS y PÉREZ, 1990). La actuación consistió en dos cortes en el solar que rodea la torre por sus lados sur y oeste y en el análisis de las estructuras emergentes de la torre. Entre las conclusiones referidas a la evolución urbana del sector, la principal para nuestros fines es la de descartar que el muro que cierra el solar hacia el oeste sea un tramo de muralla conservado, como hasta el momento se pensaba. En cuanto a la datación de la torre, la primera fase identificada corresponde a su cuerpo inferior, construido en tapial, que se data como bajomedieval, posterior al siglo XIII. Las estancias interiores, cubiertas con bóvedas de arista construidas en ladrillo, se adscriben a los siglos XIV-XV.

"Seguimiento arqueológico en Cuesta de los Cipreses" (RUIZ, 2001). Se excavó una franja de 3,5 m de anchura a lo largo del margen derecho de la calle, sin profundizar más allá de lo que requería el nuevo acerado a realizar. Respecto al tema que nos ocupa, en el extremo inferior de la misma se localizaron dos

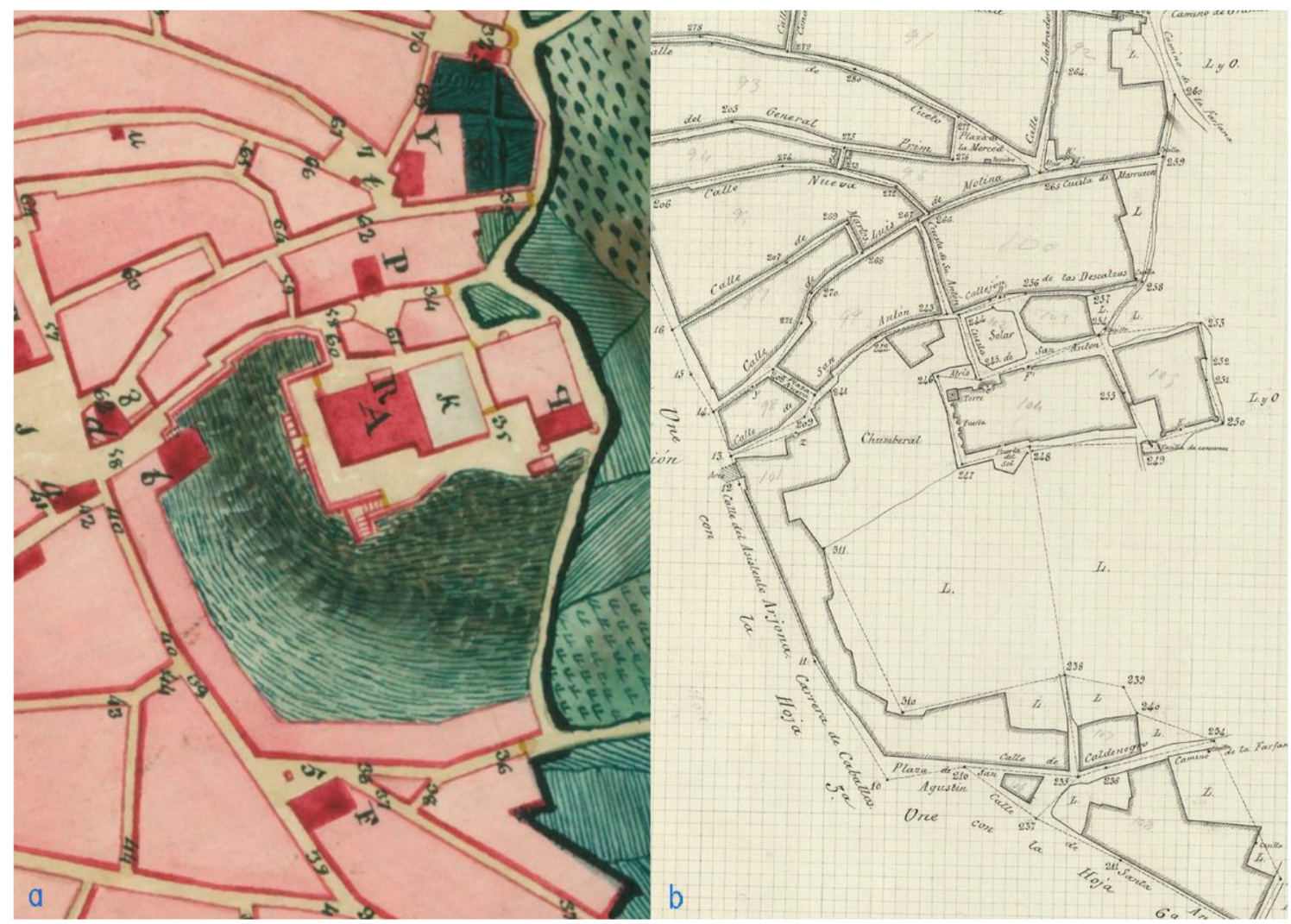

Fig. 1a. Detalle del Plano Topográfico de la Villa de Osuna y sus alrededores de 1826, escala aproximada 1:4.950 (https://bibliotecadigital.rah.es/es/consulta/registro.do?id=61334). Fig. 1b. Plano parcial de población del Instituto Geográfico y Estadístico de 1896, escala 1:2.000 (https://centrodedescargas.cnig.es/ CentroDescargas/) 
estructuras que se relacionan con una muralla, una de ellas como bastión adosado a la otra, para las que se propone una cronología mudéjar (siglos XIV y XV) o anterior. En las conclusiones se dice que estos restos corresponderían a un punto intermedio, desde la trasera de la calle Caldenegros, donde las fuentes escritas apuntaban la presencia de la muralla, hasta el enlace con los restos de los Paredones.

"El monasterio de la Encarnación de Osuna. Análisis arqueológico de los paramentos septentrionales" (VARGAS y ROMO, 2005). En este análisis se define la serie estratigráfica emergente, que se inicia con una estructura en la base de la torre situada en el extremo oriental, construida en sillarejos y muy erosionada, para la cual se propone una antigüedad superior a la fundación del primitivo hospital de la Encarnación en 1549. Dicha estructura se asocia con la existencia de "algún dispositivo defensivo (torre)", por su situación dentro del hipotético recorrido de la muralla medieval. Con objeto de poder verificar si el basamento de la fachada analizada ocultaba o servía de revestimiento a la muralla, se realizaron dos sondeos de un metro de profundidad. En ellos no se detectaron indicios claros de la existencia de un muro previo, aunque tampoco se descartaba su presencia más hacia el interior o a mayor profundidad.

"Restos en la calle Caldenegros" (resultados no publicados). Al menos desde el año 2014 se han venido realizando trabajos arqueológicos en esta zona, que llevaron en 2019 al acondicionamiento del lugar y su apertura al público. Los restos excavados comprenden un considerable tramo de muralla, así como una serie de estructuras urbanas previas a la misma. De las informaciones recogidas en prensa o publicadas en la web del ayuntamiento se obtienen los siguientes datos. La muralla se data como almohade en su fundación, mientras que las estructuras urbanas se asocian a la presencia de un arrabal extramuros, al menos desde el siglo XI. De la superposición de ambos se deduce que la muralla almohade supuso una ampliación de un recinto anterior más reducido.

\section{PLANO BASE DEL ANÁLISIS}

El proceso de trabajo parte del dibujo de un plano que es la base del análisis posterior. Este supone la reconstitución - el dibujo corregidodel plano o planos históricos más antiguos, con la incorporación al mismo de un parcelario aproximado. El documento obtenido facilita la lectura de la ciudad en su forma histórica, anterior a las transformaciones contemporáneas. El resultado del proceso descrito en este apartado es el que se muestra en la figura 2.

En Osuna tenemos la suerte de contar con un plano realizado en una fecha tan temprana como la de 1826: el Plano Topográfico de la Villa de Osuna y sus alrededores de 1826, a escala aproximada 1:4.9503. Ordenado por José Manuel de Arjona y levantado por Manuel Spínola, forma parte de una colección de siete planos de algunas de las principales ciudades del Reino de Sevilla (FAJARDO, 2016). Contiene gran cantidad de información, tanto de la extensión urbana como de los alrededores más inmediatos, incluyendo una valiosa leyenda. Su corrección geométrica sin embargo no es muy alta, por lo que será el siguiente conjunto el que utilicemos para el dibujo de nuestro plano base (fig. 1a).

Los del Instituto Geográfico y Estadístico son siete planos parciales de población, elaborados en 1896 a escala 1:2.000 y compuestos en uno completo a escala 1:5.000 en 19074. Su corrección geométrica es muy buena, mejor incluso que la de los que veremos a continuación, siete décadas después. Comparándolos con el anterior comprobamos que las transformaciones son escasas, producidas en el entorno de la iglesia mayory de la torre del Agua, el único elemento del recinto defensivo conservado que, sin embargo, no aparece señalado ni rotulado en el plano de 1826 (fig. 1b).

3. https://bibliotecadigital.rah.es/es/consulta/registro.do?id=61334

4. https://centrodedescargas.cnig.es/CentroDescargas/ 


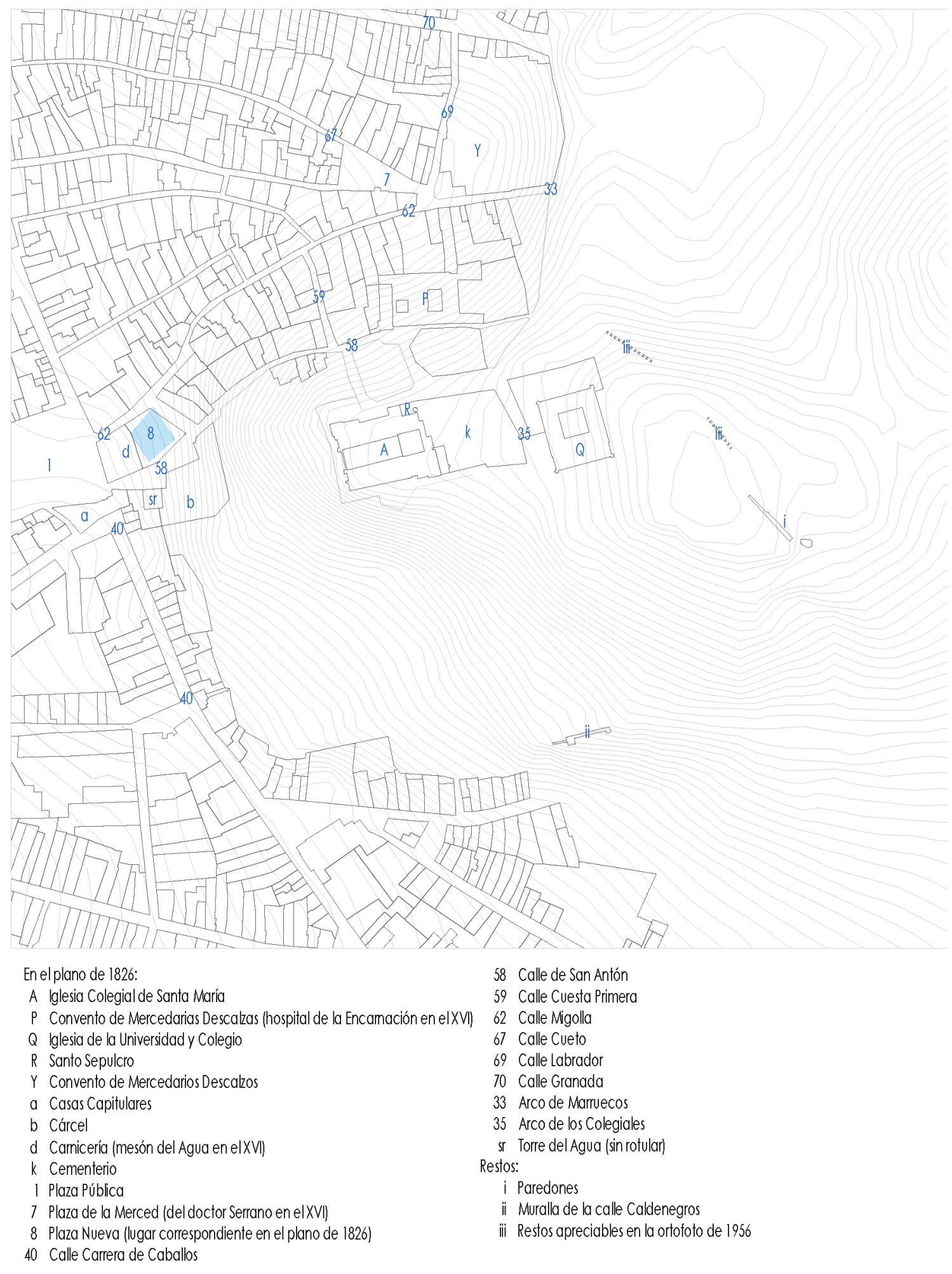

Fig. 2. Plano base del análisis. Elaboración propia. 
Los siguientes documentos manejados corresponden a los trabajos de implantación urbana del catastro, realizados en 1974, en 11 hojas a escala 1:1.0005. Como decíamos antes, su precisión deja que desear, aunque la información que nos interesa en este caso es la correspondiente al parcelario. Respecto al plano de 1896, se producen cambios en los entornos de la universidad y de la torre del Agua, junto con la aparición del nuevo barrio de La Rehoya, en la falda suroriental del cerro.

Para nuestro dibujo del plano base, hemos editado la cartografía digital actual del catastro ${ }^{6}$, retrocediendo por comparación hasta el plano de 1896, pasando por el de 1974. El parcelario aproximado se ha incorporado a partir del plano de 1974, con las modificaciones necesarias, y del plano de 1826 se ha recogido la leyenda. La topografía se ha obtenido a partir del Modelo Digital de Andalucía?. Otros documentos han servido de apoyo, aunque no se hayan incluido en el proceso de reconstitución: la cartografía urbana del Instituto de Estadística y Cartografía de Andalucía a escala 1:500, año $1994^{8}$, y los vuelos conocidos como Vuelo Americano (serie B) de 1956 y Vuelo Interministerial de $1973^{9}$.

\section{RECORRIDO NORTE}

Como se recoge en el plano de la figura 3, en este lado la muralla vendría a coincidir con la línea que dibujan los fondos de las parcelas de las calles Migolla, actual Luis de Molina, y San Antón. La presencia de restos puntuales, la continuidad del trazado y el desnivel existente entre las parcelas a uno y otro lado así lo confirman. La continuidad se pierde no obstante al llegar al convento de las Mercedarias, hospital de la Encarnación en el XVI, donde habría que justificar la solución propuesta.
En el estudio arqueológico de paramentos realizado en la fachada trasera del convento (VARGAS y ROMO, 2005) no se pudo comprobar si el muro posterior del edificio coincide con el trazado de la muralla, sin llegar tampoco a descartarlo. En dicho estudio, sin embargo, se documenta la presencia de una estructura preconventual, sobre la que apoya una torre posterior en el extremo oriental de la fachada y se sugiere su posible relación con un bastión de la muralla. De ella se dice lo siguiente: "Un elemento de tales características, en el marco espacial en el que nos encontramos y conforme a los antecedentes históricos que sitúan por esta banda el hipotético recorrido de la muralla medieval de Osuna, nos lleva a plantearnos su posible asociación con algún dispositivo defensivo (torre) -si no como conformante de la estructura original, como reflejo de su existencia soterrada u oculta bajo ella-" (Ibid.: 529). En la figura 3 aparece localizada dicha estructura, cuya posición reforzaría la correspondencia de trazado entre muralla y fachada posterior del edificio.

Algo más arriba del convento, el muro vendría a unirse con el recorrido noreste del cual, como dice Ledesma, "algunos restos que afloran de forma discontinua pueden ser identificados como vestigios de la muralla, que prosigue hasta alcanzar la alcazaba" (LEDESMA, 2003: p. 95), restos que son apreciables en la ortofotografía de 1956 sobre la que los hemos dibujado.

La puerta Nueva se ubicaba en el entorno noreste como único acceso en este frente, hasta la apertura, entre 1535 y 1539, del postigo de la calle Cuesta Primera, actual calle Abades (LEDESMA, 2003: 88).

Pensamos que su posición vendría dada por el encuentro de las calles Cueto y Migolla, proyectado sobre el trazado de la muralla, lo

\footnotetext{
5. Originales en soporte poliéster en el archivo de la Gerencia Regional de Andalucía-Sevilla. Copia facilitada por la Oficina Municipal de catastro del ayuntamiento de Osuna.

6. https://www.sedecatastro.gob.es/Accesos/SECAccDescargaDatos.aspx

7. Instituto de Estadística y Cartografía de Andalucía. Modelo Digital de Andalucía10 metros/pixel (2008-2009). En: http:// www.juntadeandalucia.es/institutodeestadisticaycartografia/lineav2/web/

8. http://www.juntadeandalucia.es/institutodeestadisticaycartografia/lineav2/web/

9. http://centrodedescargas.cnig.es/CentroDescargas/catalogo.do?Serie=FPNOA\#
} 


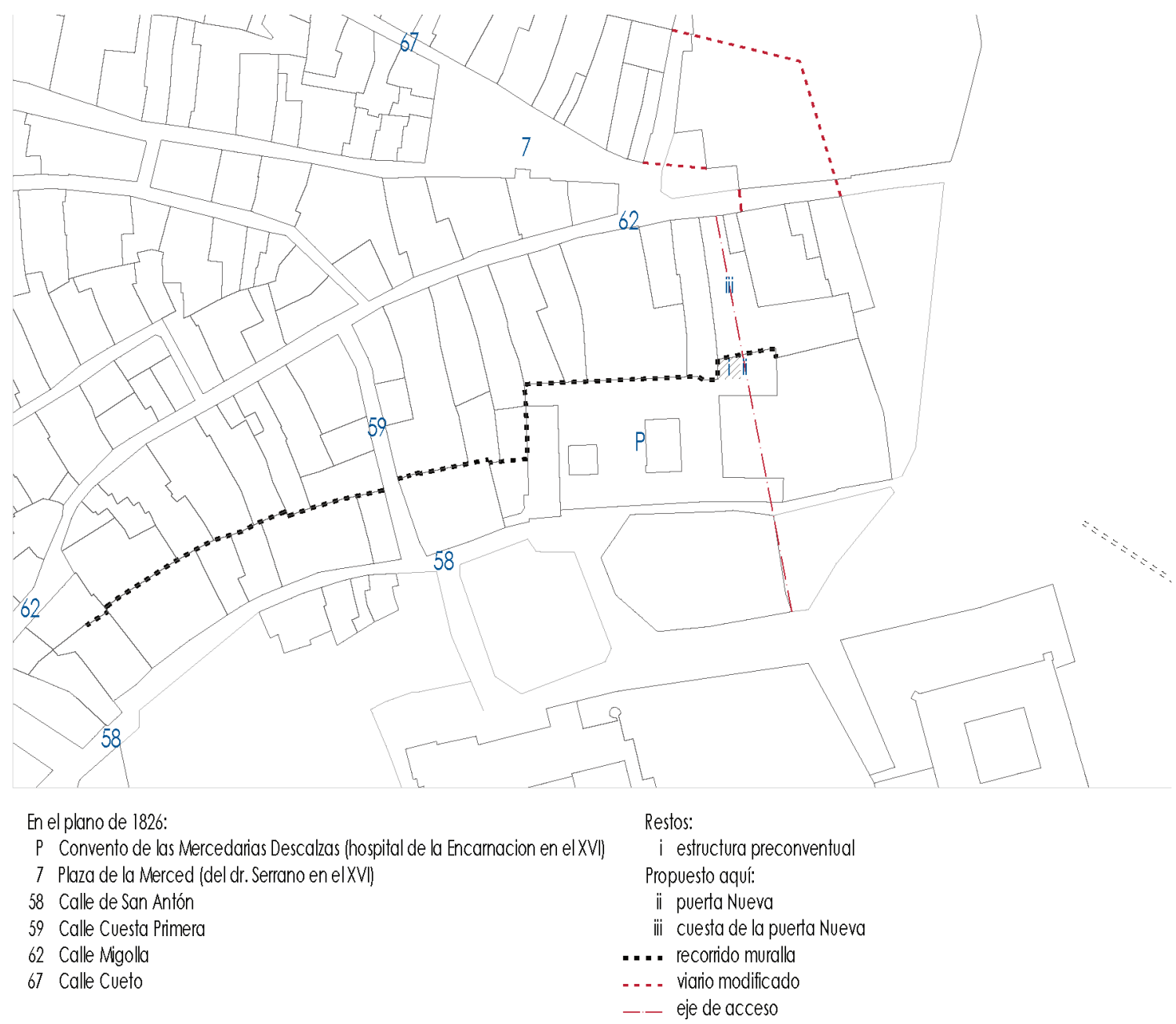

Fig. 3. Análisis del recorrido norte. Elaboración propia.

cual vendría a coincidir con la torre sugerida en el estudio de paramentos del monasterio. En la figura 3 hemos dibujado el eje de acceso correspondiente, comprobando cómo su prolongación hacia intramuros coincide con un límite de parcela y enlaza con el callejón de los Colegiales (fig. 2, n. ${ }^{\circ}$ 35). Distintos argumentos apoyan esta propuesta.

En lo que se refiere a las descripciones recogidas en los documentos, estas son bastante imprecisas, aunque compatibles con la ubicación propuesta. En una de las más completas, aunque algo tardía, de 1622, se describe un recorrido que va, desde la calle Granada, bajando por la calle Labrador hasta alcanzar la plazuela del doctor Serrano y, desde allí, "por la calle Migolla arriba... por donde se sube la cuesta de la Puerta Nueva..." (LEDESMA, 2003:
94). La plazuela corresponde a la plaza de la Merced y la cuesta de la puerta Nueva podría ser la que salvase la distancia existente entre la calle Migolla y la puerta.

La forma del viario es coherente con la posición de la puerta, aunque quizás no de forma evidente. La formación sucesiva, no simultánea, de las calles Migolla y Cueto explicaría que la calle Cueto no parta desde la misma puerta, sino desde la calle Migolla, "cuesta abajo". La calle Migolla habría surgido en primer lugar, a modo de "ronda" por la aparición de un tejido residencial apoyado en la muralla, mientras que la calle Cueto lo haría con posterioridad, como recorrido desde el entorno de la puerta Nueva hasta la plaza de Santo Domingo, foco de crecimiento extramuros. Hacia intramuros, hemos visto cómo el eje de acceso enlaza con 
el callejón de los Colegiales, el cual daba acceso a la plaza que separaba los edificios de la universidad y del palacio-fortaleza (RUIZ, 2005).

En el grabado de Hoefnagel, realizado en la década de los sesenta del siglo XVI, a pesar de los errores que tiene -que se explican por su carácter más icónico que documentalpodemos identificar con bastante seguridad la fachada trasera del edificio del convento. En su extremo oriental, aparecen dibujadas dos torres almenadas que sobresalen y que, según la hipótesis planteada, podrían corresponder con la puerta Nueva (fig. 4).

En cuanto a la configuración del arrabal en el entorno de la puerta, como señala Ledesma, se cerraba en este extremo. Así se deduce de los repetidos intentos de apertura al final de la calle Migolla para conectar con el camino de Granada ${ }^{10}$. En la figura 3 hemos dibujado en línea discontinua el contorno aproximado correspondiente a la situación de cierre del espacio en el XVI. Actualmente la salida se produce en dos puntos, la calle Labrador y la cuesta de Marruecos (fig. 2, n.os 69 y 33), ninguna de las cuales existiría antes de 1593, fecha en la que aún se insiste en la necesidad de abrir. La primera en aparecer habría sido la calle Labrador, mencionada en el documento antes citado, de 1622. Con posterioridad, hacia mediados del siglo, se produce la instalación del convento de Mercedarios Descalzos (fig. 2, Y), lo que debió de suponer una importante transformación del sector, parte de la cual pudo haber sido la apertura de la cuesta de Marruecos.

\section{RECORRIDO OESTE}

El apartado remite al plano de la figura 5. En nuestra propuesta, al sur de la torre del Agua, la muralla seguiría la línea de fondos de parcela de las casas de la Carrera de Caballos hasta el número 31 de la calle actual. A partir de aquí, y hasta el número 3 de la calle de San Agustín, el fondo de algunas parcelas

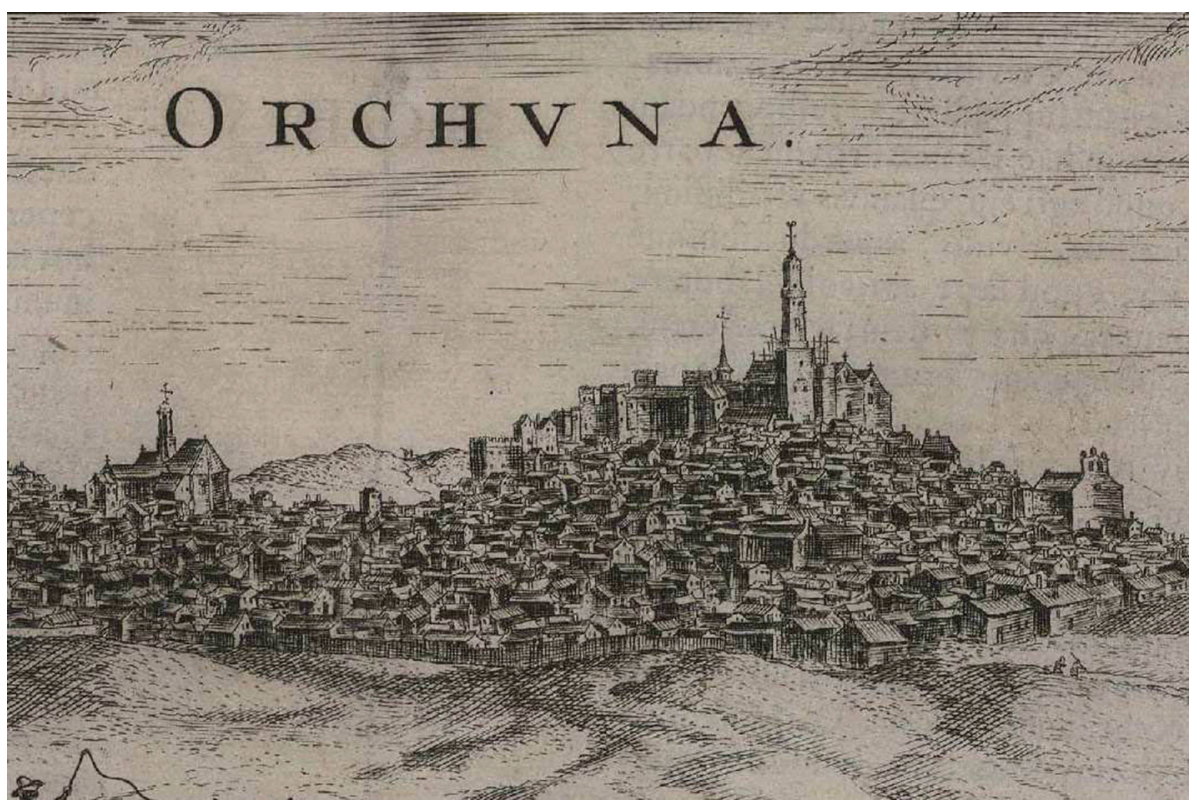

Fig. 4. Joris Hoefnagel. Grabado de Osuna incluido en el $4^{\circ}$ tomo del Civitates orbis terrarum, primera edición de 1588 (http://bdh.bne.es/bnesearch/detalle/3775533)

10. El camino de Granada discurría al norte, enlazando al este con la calle de Granada. En 1562 se produce la primera iniciativa en ese sentido, aunque no se llega a abrir la calle. En ese año "el concejo alude a las distintas ocasiones en que se ha debatido el asunto y decide, finalmente, comprar un inmueble que se hallaba frente a la embocadura de la calle Migolla y derribarlo para abrir un acceso directo al camino de Granada" (LEDESMA, 2003: 91). 


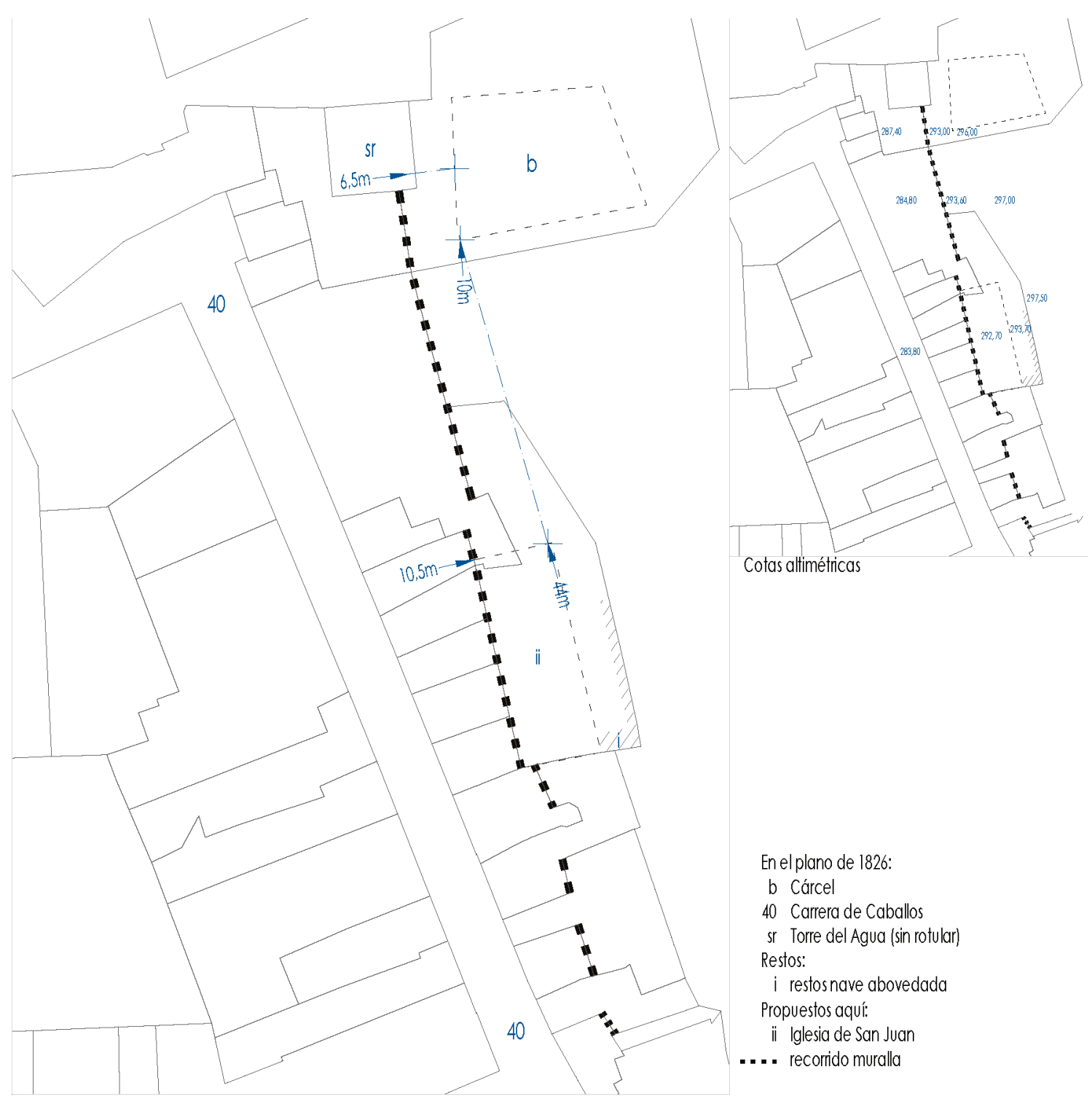

Fig. 5. Análisis del recorrido oeste. Elaboración propia.

aumenta, extendiéndose por detrás de las vecinas, de forma que la alineación propuesta sigue de forma discontinua. En concreto, como podemos ver en el plano de la figura 6, las parcelas cuyo fondo aumenta son los números 33 , 35 y 39, siendo evidente en las dos primeras que se ha producido un crecimiento sobre la ladera: el número 35 ocupa las traseras de 33 y 37 , mientras que el número 33 ocupa las de 29 y 31. En el mismo plano se observa además que la altura edificada se reduce en la parte correspondiente a la ampliación: de 4 a 2 plantas para el número 33, y de 2 a 1 planta para el 35 , lo cual pensamos que tiene relación con el aumento de cota de la ladera.
A diferencia de lo que ocurre en la calle Migolla, la Carrera de Caballos no surge por la organización de un tejido residencial apoyado en la muralla, sino que existe previamente, como camino a Teba. Esto justifica el escaso fondo de las parcelas, así como la ampliación hacia atrás de algunas de ellas.

Del lado opuesto a la calle aparece una parcela de gran tamaño, básicamente una plataforma rectangular de 17 por 29 metros, que se prolonga al norte con forma irregular, y que relacionada con la ubicación de la desaparecida iglesia de San Juan. El análisis de la topografía del tramo viene a reforzar el trazado que 


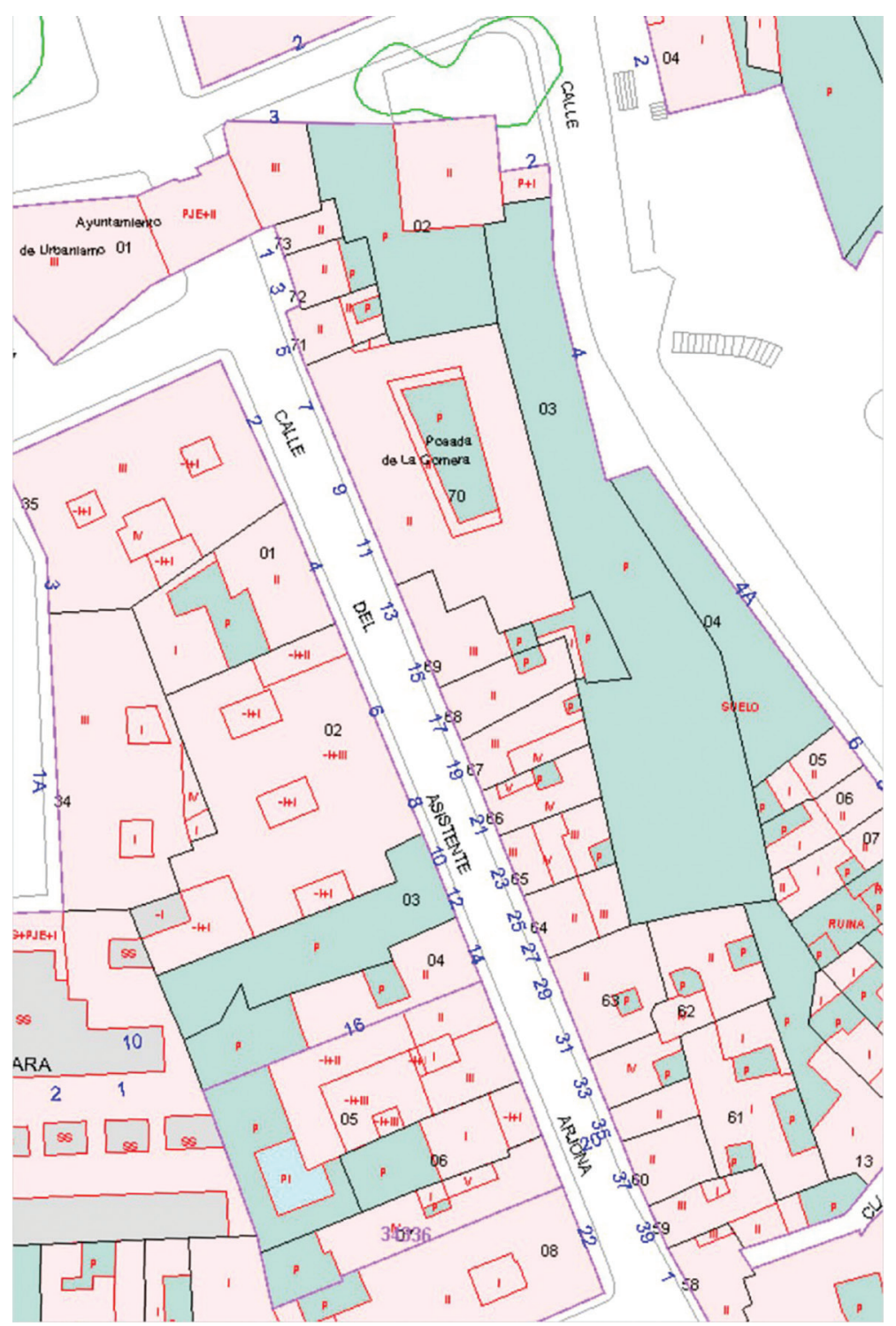

Fig. 6. Detalle del plano actual de catastro para el mismo sector (https://www1.sedecatastro.gob.es/ cartografia/mapa.aspx)

proponemos. La diferencia de cota entre uno y otro lado del mismo es de 5,60 metros junto a la torre, de 8,80 más abajo y de 8,70 en la plataforma mencionada. Aunque la actual calle de la Torre también se eleva progresivamente hacia el sur, el desnivel en este caso no supera los 4,80 metros. El mayor salto de cota se produce por tanto en el recorrido propuesto, en el que la muralla haría de contención del terreno. Algunos datos parecen contradecir sin embargo esta hipótesis, aunque creemos que se pueden explicar.

El estudio arqueológico realizado en la torre del Agua, previo a su adecuación como museo arqueológico (SALAS y PÉREZ, 1990), concluye que el muro inmediato a la torre al sur no pertenece, como se pensaba hasta entonces, a la muralla. El motivo es el hallazgo de una calle, datada de época moderna, que pasa por debajo del mismo. El muro apoya directamente sobre la calle, sin cimentación, y tampoco traba con la torre, de lo que se deduce que es posterior. Pensamos en cambio que esto se refiere exclusivamente a la consideración del muro como resto material de la muralla y no a su trazado, que podría coincidir. 
Otro aspecto contradictorio son las referencias a la desaparecida iglesia de San Juan como situada a "extramuros". Un informe de 1765 así la describe, cuando dice que "informó el dicho maestro se había hecho tan grande la broza que impedía el paso franco a la dicha iglesia de señor San Juan, especialmente en los tiempos de agua y de hallarse extramuros y sin vecindad, por estar por un lado la muralla que va desde la Torre del Agua a dicha capilla e iglesia de señor San Juan, y el otro el campo..." (LEDESMA, 2003: 154). Sin embargo, la referencia al "campo" no puede ser por estas fechas sino al antiguo intramuros, que ya por entonces se encontraba totalmente despoblado, de forma que la expresión "extramuros" vendría empleada en relación con una nueva situación. Esta es la reflejada en el plano de Spínola, sesenta años posterior. En él queda claro que la antigua relación campo-ciudad que delimitaba la muralla en este tramo se ha visto invertida ${ }^{11}$.

En el citado informe se describe el solar resultante de la obra que solicitan los hermanos de la cofradía de la Caridad, titulares entonces de la iglesia de San Juan. A partir de esta descripción y de su traslado al plano, llegamos a nuestra propuesta de ubicación de la iglesia (fig. 5). Con objeto de acotar el espacio e impedir su abandono, los hermanos solicitan licencia "para echar una pared desde la iglesia del señor San Juan donde está sita - la cofradía-, hasta el arco que une la Torre del Agua con la Cárcel pública..." (LEDESMA, 2003: 153) "...para lo que hicieron que dicho alarife midiese el expresado terreno y medido se halló que desde dicho arco donde debía ponerse la puerta a la esquina de la Cárcel había doce varas y media (unos $10 \mathrm{~m}$ ) y de ancho ocho (aproximadamente $6,5 \mathrm{~m}$ ) y desde la citada esquina de la Cárcel a donde debe principiar la pared hasta la esquina de dicha iglesia había poco más de cincuenta y cinco varas (unos 44 m) y de ancho trece (aproximadamente 10,5 m)" (LEDESMA 2003: 155).

El "dicho arco donde debía ponerse la puerta" es el que sostiene el pasadizo que comunicaba la cárcel con la torre y que da paso al solar en cuestión. Trasladando las dimensiones al plano, la "esquina de la Cárcel" coincide con el quiebro del muro que cierra el actual callejón hacia el este. Desde este punto, las 55 varas, medidas en paralelo al cerramiento oeste del callejón "hasta la esquina de dicha iglesia", nos llevan al punto a partir del cual se abre la plataforma rectangular.

La plataforma está dividida en dos partes por un desnivel de un metro. La anchura del nivel inferior viene a coincidir con las 13 varas del informe, mientras que el nivel superior tiene unos 6 metros de anchura. El informe hace referencia a "la esquina de la iglesia", sin indicar si las 13 varas de anchura corresponden a su fachada, que es lo que hemos supuesto.

Existen restos circunscritos a la parte más elevada, que interpretamos como pertenecientes a una nave y a una capilla en el extremo sur cubiertas mediante bóvedas. Pensamos que estos restos podrían pertenecer a la iglesia, aunque como cuerpo adosado, por el desnivel del suelo.

La iglesia de San Juan servía como ayuda de parroquia de la iglesia mayor. Su datación se desconoce, pero sabemos de su existencia en 1570, cuando se dice de ella que "estaba reedificada” (LEDESMA, 2003: 79). Formaba parte de uno de los recorridos principales de la desaparecida trama medieval al cual daba nombre. La importancia de la calle de San Juan se deduce del hecho de ser parte principal del recorrido intramuros que seguía la procesión del Corpus, hasta la apertura de la "nueva calle" que veremos en el siguiente apartado (LEDESMA, 2000: 215).

11. En el plano, cuyo objeto parece ser el establecer una delimitación fiscal de la población, se dibujan como puertas o controles las salidas al campo de cada una de las calles, quedando fuera de estos límites el cerro de la Colegiata, lo cual viene a reforzar la idea del mismo como "campo". 


\section{RECORRIDO NOROESTE}

El tramo noroccidental es el que mayor transformación ha experimentado por ser el de contacto con la plaza y los edificios asociados a ella, sin que quede rastro de la muralla, ni de su recorrido, ni de la posición y configuración en planta de la puerta. Sin embargo, la centralidad de este entorno hace que abunden las referencias documentales a los edificios y espacios localizados en él. Aunque estas son por lo general breves y confusas en conjunto, creemos que es posible, en un repaso atento de las mismas, extraer algunas conclusiones. Para hacerlo de forma ordenada comenzaremos con las que se refieren al espacio extramuros y continuaremos por las que lo hacen al intramuros.

El apartado remite al plano de la figura 7.

\subsection{Entorno extramuros}

En este entorno se mencionan repetidamente una serie de elementos, la puerta del Agua, la torre del Agua, el mesón del Agua, así como la alberca y otras casas y tiendas. Asimismo se mencionan "la calle que dicen de la Puerta del Agua" y "la callejuela del alberca"12. Intentaremos deducir la posición relativa de estos elementos a partir de algunas escuetas pero significativas descripciones.

Desde 1548 tenemos noticias de la existencia del mesón del Agua en el lugar (LEDESMA, 2003: 102). Posteriormente, en distintos documentos se mencionan casas en el inicio de la calle Migolla que lindan por detrás con el mesón, y en un documento de 1582 se sitúa a este como próximo a la Puerta del Agua, "debajo de ella" (Ibid..: 105). Por otro lado, en 1583 se describe la situación de una tienda como "a la puerta del agua...", junto a la "callejuela del alberca...". Cinco años más tarde se dice de la misma que está "en la calle que dicen de la Puerta del Agua frontero del Mesón del Agua - que por la cercanía con la fuente recibe tal apelativo-y linde con el alberca..." (Ibid.: 103). De estas citas se puede deducir una sucesión de elementos, de norte a sur, que sería la siguiente: calle Migolla, casas, mesón del Agua, puerta y calle de la puerta del Agua, tienda y alberca.

También en 1583 se da la ubicación de la casa de un tal Ramírez y se dice de ella que está "en la plaza publica de ella (la villa) junto a la Puerta del Agua linde con la casa del alberca e con el muro y Torre del Agua..." (Ibid.: 103). Esta casa y la tienda mencionada antes parecen compartir ubicación, lo cual es posible, ya que la tienda podría ocupar la planta baja de la vivienda. La cita además menciona la puerta y la torre como elementos diferenciados, lo cual creemos significativo. Es posible que la puerta estuviera separada de la torre y que esta última tuviese como finalidad principal la defensa y quizás el almacenamiento del agua de la fuente Vieja, y no tanto flanquear el acceso.

La idea a veces apuntada de que la torre era una de las dos que flanqueaban la puerta puede tener su origen en la descripción de la muralla que a mediados del XVIII hace García de Córdoba, en la que se presenta como un "fortísimo muro, que aún hoy se descubre entero por partes", en el que se abrían cuatro puertas, todas ellas flanqueadas por dos torres, denominadas del Agua, de Granada, Nueva y del Caño (LEDESMA, 2003: 56). La descripción concuerda con lo que hemos visto antes para la puerta Nueva, pero no con lo que acabamos de ver para la puerta del Agua. Sin embargo, hay que decir que se trata de una descripción idealizada y no muy fiable, ya que para entonces la muralla habría desaparecido en gran parte $y$, efectivamente, en el tramo correspondiente a la puerta del Agua.

12. La denominación de todos ellos como "del Agua” se debe a la proximidad de la fuente Vieja, punto principal, quizás único hasta la puesta en funcionamiento de la fuente Nueva hacia 1529, de abastecimiento de agua. 


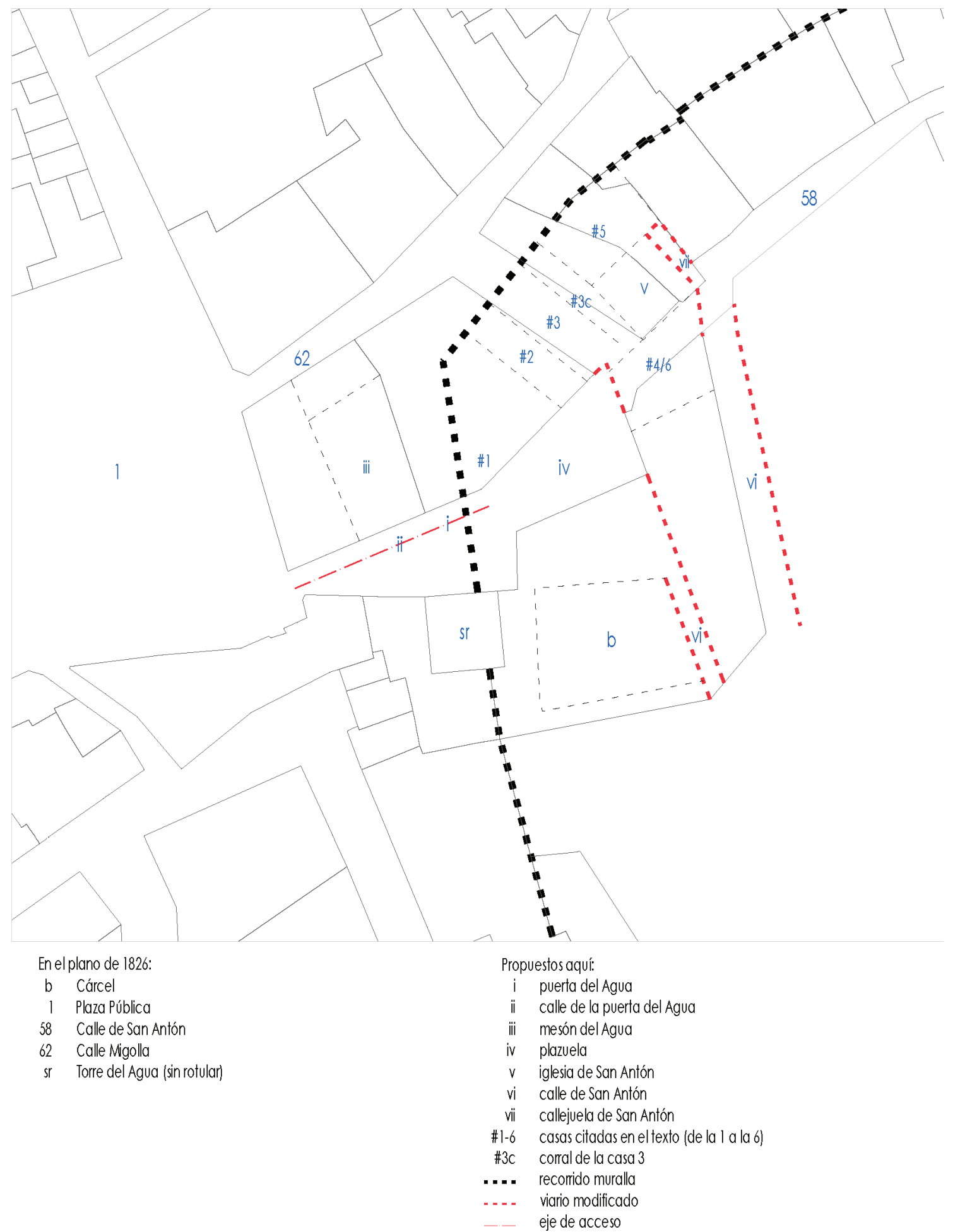

Fig. 7. Análisis del recorrido noroeste. Elaboración propia.

Desde finales del XVI y hasta entrado el XIX, se suceden una serie de documentos relativos a la instalación de las carnicerías en el sitio del mesón del Agua que también contienen datos a tener en cuenta. Hacia 1599 se dice que se había tomado "un pedazo del Mesón del Agua... para hacer carnicería donde la tiene fecha en el cuarto del dicho mesón que sale a la calle del Agua que desciende de la Fuente Vieja de esta villa a la plaza..." (LEDESMA, 2003: 
129). Sabemos que en esta fecha ya había concluido la apertura de la "nueva calle" a la que nos referiremos más adelante. Si nuestra hipótesis de localización de la puerta es acertada, la "nueva calle", en su encuentro con la muralla, vendría a coincidir con la ya existente. Así la "calle del Agua que desciende de la Fuente Vieja de esta villa a la plaza” mencionada en este documento se correspondería con la "calle que dicen de la Puerta del Agua" del documento de 1588 que hemos visto antes.

Por un informe de 1682 sobre el estado ruinoso de la muralla y la necesidad de su demolición, sabemos que la carnicería lindaba con esta, que se encontraba en una cota más elevada (Ibid.: 130). Hacia atrás había un espacio no ocupado que, casi un siglo más tarde, se describe como "cerro que domina la referida fabrica (la carnicería) por componerse todo él de escombro y tierra" y como "muladar" o basurero en el que aún quedarían vestigios de la muralla, como se dice en sendos documentos fechados en el mismo año de 1768 (Ibid.: 131).

En 1769 se habían construido unas nuevas instalaciones, ampliadas para albergar también la pescadería, de las que se dice que estaban "en la parte del sitio que tenían las antiguas y que para su extensión se usó de alguna del solar que esta inmediato a ellas y que pertenece a esta villa y a que de resultas de dicha obra se ha quedado un pedazo de sitio que le corresponde por la parte de abajo de las casas carnicerías" (Ibid:: 130). Pensamos que esta ampliación debió de realizarse ocupando las casas colindantes hacia la calle Migolla ${ }^{13}$, mientras que el "pedazo de sitio que le corresponde por la parte de abajo de las casas carnicerías" que ha quedado, podría referirse al espacio comprendido entre las carnicerías y la plaza.
Esto estaría en consonancia con lo representado en el plano de 1826 (fig. 1, d). En él aparece rotulada la carnicería llegando hasta la calle Migolla, pero no hasta la plaza, mientras que en el lindero oriental aparece un espacio rotulado como plaza Nueva ${ }^{14}$, que correspondería al espacio que antes hemos visto denominado como cerro y muladar.

La construcción de los edificios del casino y del teatro hacia 1890 supuso una transformación de este sector que hace difícil reconocer su evolución $n^{15}$. Sin embargo, con las reservas que plantean los errores geométricos del plano de Spínola, podemos intentarlo comparando este último con nuestro plano de análisis, basado en el de 1896. Al hacerlo comprobamos que el edificio del casino se corresponde básicamente con la manzana del mesón del Agua, mientras que el edificio del teatro ocuparía el espacio de la plaza Nueva, llegando a rebasarlo. Según esto, la calle rotulada en la actualidad como plaza Nueva habría supuesto el derribo de las casas colindantes con la antigua plaza. Las casas que dan fachada a la calle plaza Nueva y a la esquina con la calle de San Antón, numeradas del 1 al 7 en el plano de catastro de 1974, formarían parte de esta operación (fig. 8$)^{16}$.

El recorrido asignado a la muralla, a falta de más datos, viene a cerrar el ángulo en prolongación de los recorridos, conocido y propuesto, de los tramos norte y oeste respectivamente, entendiéndolo como la solución más simple.

\subsection{Entorno intramuros}

Los documentos relativos a este entorno son muy confusos. En ellos se alude a algunos

13. Casas que el ayuntamiento tenía compradas en 1608 con este fin (LEDESMA, 2003: 130).

14. El nombre de plaza Nueva que recibe este espacio parece tener su origen en el proyecto de instalación en el mismo de la plaza de hortalizas, como traslado desde la plaza mayor para la reforma de esta última (LEDESMA, 2003: 131).

15. El casino de Osuna se instala inicialmente en 1852, ocupando una gran casa con dos patios situada en la plaza. Más tarde, en 1890, se levanta un nuevo edificio, que hay que poner en relación con la construcción del teatro, ya que ambas actuaciones se producen hacia 1890 y se encargan al mismo arquitecto, Juan Talavera de la Vega. Los edificios compartían parcela y presentaban una división horizontal de la propiedad en una pequeña parte (RANGEL, 2005). El edificio del casino fue ampliado en 1921 con la compra de la casa contigua que completaba el frente hacia la plaza (LUQUE-COBOS, 2016).

16. Observamos además en este plano, que el límite entre la casa número 1 y la casa número 6 de la calle Luis de Molina sigue la alineación de la muralla. 


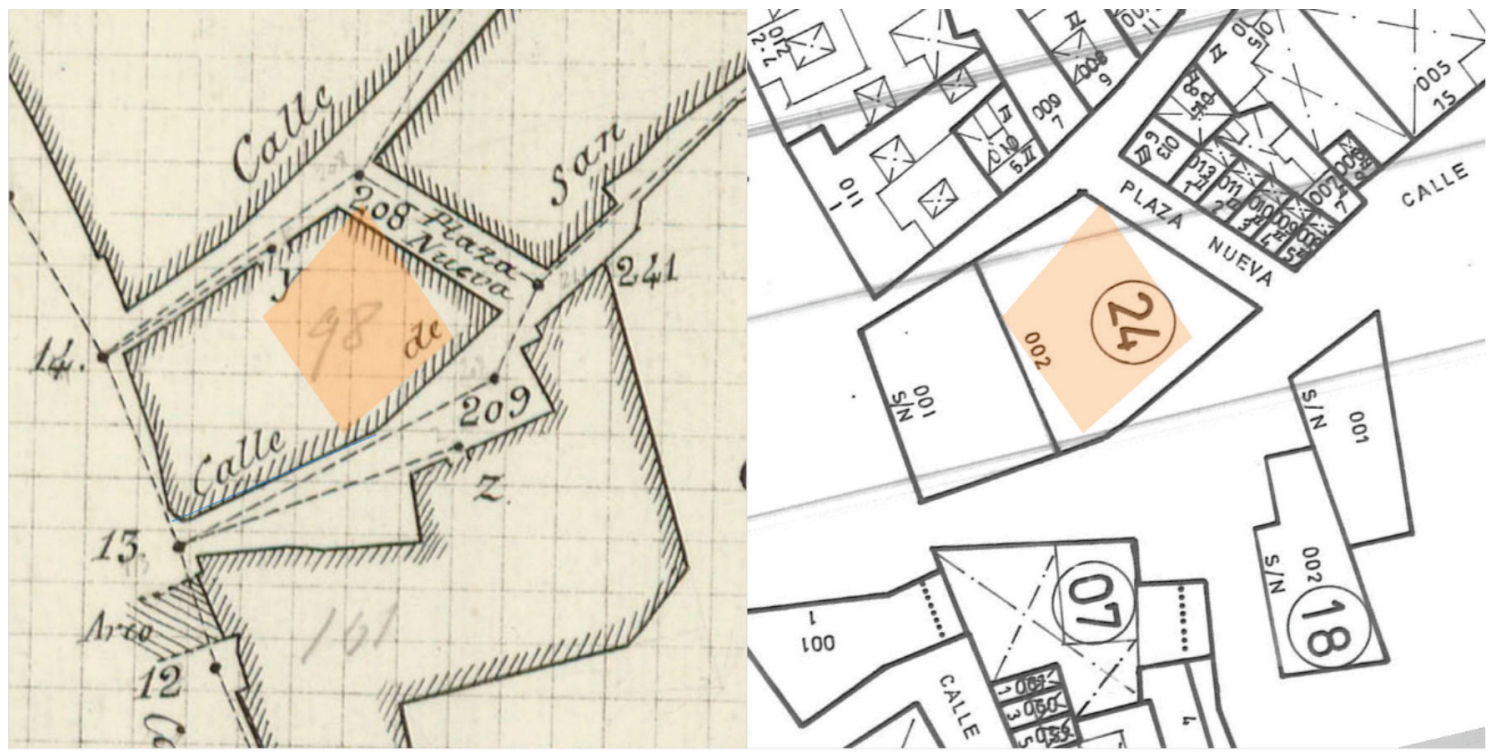

Espacio que ocupa la plaza Nueva en el plano de 1826.

Fig. 8. Detalle del entorno del espacio de la plaza Nueva en los planos de 1896 y de 1974 con superposición del espacio que esta ocupa en el plano de 1826.

elementos de referencia como son la puerta del Agua, la cárcel, la fuente Vieja, la iglesia de San Antón, la plazuela de la fuente Vieja o la "calle", "cantillo" y "callejuela de San Antón". La cárcel mantuvo desde entonces la misma ubicación que aparece en el plano de 1826, al este de la torre del Agua, a la cual estuvo siempre asociada, mientras que la fuente Vieja parece que estuvo inicialmente en sus inmediaciones, hasta que en 1576 se muda al centro de la plazuela del mismo nombre (LEDESMA, 2003: 106). De la iglesia de San Antón sin embargo se desconoce su ubicación.

A continuación revisamos el contenido de los documentos que nos han parecido más significativos, alusivos a algunas casas localizadas en el entorno, analizando las relaciones de posición entre ellas y con los elementos de referencia. Recogemos literalmente las descripciones manejadas, subrayando en ellas los elementos mencionados. Hemos identificado las distintas casas que aparecen mediante un número para facilitar el análisis.

1554. Diego de Cepeda vende a Juan del Castillo "dos casas de morada... junto a la Puerta del Agua que son la una que está junto a la dicha puerta y llega a ella (1) y la otra que está más arriba frontero de la calle de Santo Antón (2) e son en linde con una casa que yo - Diego Cepeda- di a tributo a Juan Carretero espartero (3) ... e linde con el adarve..." (LEDESMA, 2003: 107).

1565. Venta de una casa a Mariana Gómez (4), situada "en la calle de Santo Antón alinde con las casas de Juan Carretero espartero (3) y la iglesia del señor Santo Antón..." (Ibid.: 106).

1576. Diego López Machado dio a renta una casa que poseía "en el cantillo de la calle de Santo Antón que alinda con la ermita de Santo Antón... (5)" (Ibid.: 108).

1579. Venta de Juan Carretero a López Machado "de un pedazo de corral... en las casas de nuestra morada (3) que alinda con las paredes de señor Santo Antón y con la callejuela de encima de Santo Antón y con las casas..." de Diego López Machado (5) (Ibid.: 108).

1582. La viuda de Juan Carretero, Isabel Sánchez, garantizaba una memoria de misas con una casa (3) "que es en la plazuela de la 
Fuente Vieja..." colindante con las viviendas de Mariana Gómez (4) y de su yerno, Marcos Merchán (6) (Ibid.: 106).

Hacia finales del XVI se produce la reforma del entorno noroccidental con la apertura de una "nueva calle" para comunicar directamente la plaza pública con la iglesia. El tema se trata por primera vez en 1576 y en 1583 se adopta el acuerdo para su ejecución. En los documentos relacionados con el acuerdo de apertura de la misma, en 1583, se puede leer que la autoridad competente "tiene tratado y concertado con el concejo de esta villa se abra una calle que vaya desde el arco de la Puerta del Agua derecha a la iglesia Colegial..." (LEDESMA, 2003: 112). Las obras se inician en 1587 y se prolongan hasta 1592 y en ellas se vieron implicadas varias casas. La siguiente cita tiene que ver con la compra de estas.

1583. "Para ello es necesario derribar la vivienda de Mariana Gómez (4), que se localiza frente al arco de la mencionada puerta, punto desde el cual ha de arrancar la nueva vía, entre la calle de San Antón y la casa que allí poseían los herederos de Juan Carretero (3) El texto se repite casi literalmente en la escritura de venta de la propiedad de Marcos Merchán (6). Esta última se había alquilado unos meses atrás y en la escritura se localiza "enfrente de la fuente vieja linde con las casas de Mariana Gómez" (Ibid.: 112).

Como decíamos, es difícil a partir de estos documentos hacerse una idea de la configuración del entorno. Para ello intentaremos ordenar la información identificando los elementos que aparecen, así como las relaciones de posición señaladas entre ellos que se reducen a cuatro: en, junto $a$, frente $a$, y colindante con. Hemos supuesto que la casa del espartero Juan Carretero (3) es la misma que más tarde aparece como perteneciente a su viuda y a sus herederos. Todo esto se ha trasladado a la siguiente tabla.

Tabla 1. Relaciones de posición entre casas documentadas y elementos de referencia en el entorno intramuros de la puerta del Agua.

\begin{tabular}{|c|c|c|c|c|c|}
\hline & EN & JUNTO A & FRENTE A & COLINDANTE CON & FECHA \\
\hline casa 1 & & $\begin{array}{l}\text { puerta del } \\
\text { Agua }\end{array}$ & & adarve & 1554 \\
\hline casa 2 & & & $\begin{array}{l}\text { calle de San } \\
\text { Antón }\end{array}$ & $\begin{array}{l}\text { casa } 3 \\
\text { adarve }\end{array}$ & 1554 \\
\hline casa 4 & calle de San Antón & & & $\begin{array}{l}\text { casa } 3 \\
\text { San Antón }\end{array}$ & 1565 \\
\hline casa 5 & $\begin{array}{l}\text { "cantillo de la calle } \\
\text { de San Antón" }\end{array}$ & & & San Antón & 1576 \\
\hline $\begin{array}{l}\text { casa } 3 \\
\text { (corral) }\end{array}$ & & & & $\begin{array}{l}\text { San Antón } \\
\text { "callejuela encima } \\
\text { de San Antón" } \\
\text { casa } 5\end{array}$ & 1579 \\
\hline casa 3 & plazuela & & & $\begin{array}{l}\text { casa } 4 \\
\text { casa } 6\end{array}$ & 1582 \\
\hline casa 4 & & & $\begin{array}{l}\text { "arco de la } \\
\text { puerta del Agua" }\end{array}$ & & 1583 \\
\hline casa 6 & & & fuente Vieja & casa 4 & 1583 \\
\hline
\end{tabular}


De las relaciones de colindancia se deduce que las casas, desde la numerada como 2 a la 6 , así como la iglesia de San Antón, estaban en un entorno muy próximo. Deducir de la información anterior sus posiciones relativas podría llevarnos a esbozar la situación anterior a la apertura de la "nueva calle", así como a ubicar la iglesia de San Antón. Es lo que hemos hecho, intentando encajar el puzle de forma encadenada, como se explica a continuación y se muestra en la figura 7.

Las casas 2 y 3 son colindantes y esta última linda, a través de su corral, con la casa 5. Además, la casa 2 linda con el adarve, de ahí que las consideremos una a continuación de otra, y del lado de la muralla. Hemos supuesto que la casa 2 estaba en la plaza, por indicarse como "más arriba" de la casa 1 , que está junto a la puerta, y a pesar de que aparece situada como "frontero de la calle de Santo Antón", por el motivo que luego explicaremos.

El corral de la casa 3 y las casas 4 y 5 lindaban con San Antón. Esto nos hace pensar en una posición interior para la iglesia y rodeada en buena parte de su perímetro. La casa 5, por otro lado, está "en el cantillo de la calle de San Antón". Hemos considerado que las expresiones "cantillo" y "callejuela encima de Santo Antón" se refieren a lo mismo, una calle menor asociada al templo en el lado más alto de la pendiente, como se entiende por esta última.

Las casas de Mariana Gómez (4) y la de su yerno (6), las dos afectadas por la apertura de la "nueva calle", coinciden en ubicación (frente al arco de la puerta del Agua la primera y enfrente de la fuente Vieja la segunda), lindando entre sí y ambas con la de Juan Carretero, por lo que hemos optado por englobarlas en una única posición.

Las distintas referencias a la calle de San Antón (en la calle para la casa 4 y frente a la calle para la casa 2) nos llevan a pensar que se asignara este nombre a un recorrido zigzagueante que conectara la plaza con la iglesia, pasando por la ermita.
Todo esto nos ha llevado a la distribución mostrada en la imagen. Si bien hay que decir que queda algún cabo suelto al que no se ha encontrado solución, esta respondería básicamente a lo descrito en los documentos y, lo que consideramos más importante, sería coherente con la forma del plano.

En este, San Antón se sitúa en el extremo inferior de la cuesta que lleva a santa María. Como ermita, habría sido un edificio aislado en su origen, situado en uno de los caminos que partían desde el núcleo de la villa hacia la salida de la puerta del Agua. La ermita acabaría viéndose rodeada por casas, lo que explicaría la necesidad de la callejuela o cantillo, posiblemente para salvar el acceso.

Por otro lado, la posición de la iglesia explicaría el quiebro que presenta la "nueva calle" en este punto. Quiebro que ya aparece en el plano de 1826, aunque desplazado más arriba, pensamos que por un error geométrico.

El hecho de que San Antón no aparezca rotulado en el plano de Spínola nos hace pensar que ya había desaparecido para entonces. De no ser así, lo que parece seguro es que la reforma del sector que vimos anteriormente, ocasionada por la construcción del teatro y la plaza Nueva, habría hecho desaparecer cualquier resto.

\section{CONCLUSIÓN}

El estudio sintético del plano, estudios arqueológicos y documentos ha permitido, no solo contextualizar el conocimiento ya existente, sino realizar nuevas aportaciones de forma razonada, siendo conscientes de que estas constituyen hipótesis que solo nuevos hallazgos materiales o documentales pueden confirmar o desmentir.

Tras haber realizado el estudio de la muralla urbana en tres partes, recorridos norte, oeste y noroeste, la imagen de conjunto se muestra en el plano de la figura 9 en un encuadre completo, que incluye los restos materiales 


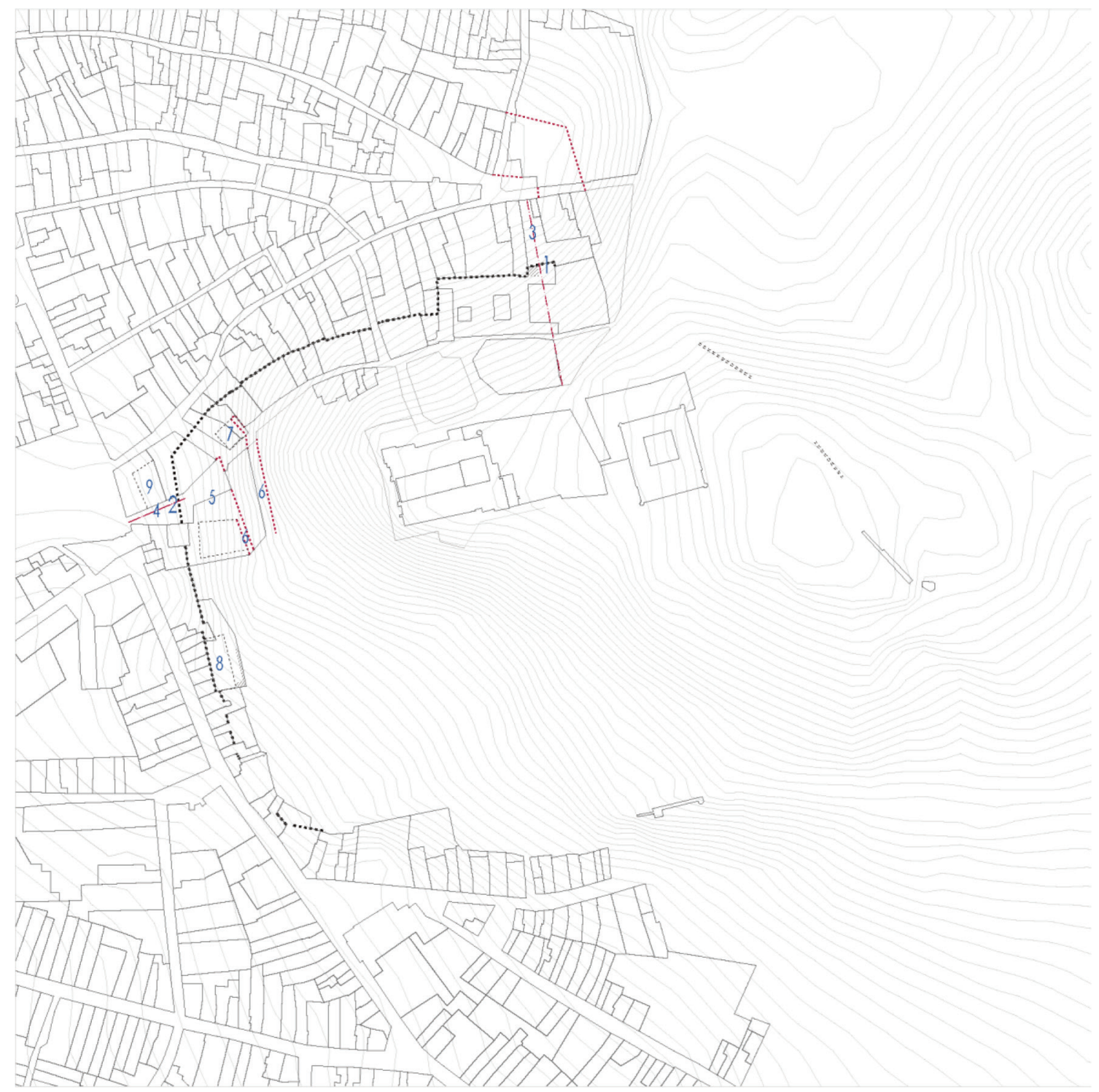

Elementos propuestos:

1 puerta Nueva

2 puerta del Agua

3 cuesta de la puerta Nueva

4 calle de la puerta del Agua

5 plazuela

6 calle de San Antón

7 Iglesia de San Antón

8 Iglesia de San Juan

9 Mesón del Agua

-..- recorrido muralla

- . - viario modificado

- - eje de acceso

Fig. 9. Síntesis de conjunto. Elaboración propia.

existentes en el resto del perímetro -Paredones y muralla de la calle Caldenegros.

Salvo el recorrido norte, sobre el que existen más evidencias, el resto del dibujo supone una propuesta original referida al trazado de la muralla, posición de las puertas Nueva y del Agua y ubicación de las iglesias de San Juan y de San Antón. Además se llega a proponer la posible configuración urbana en el entorno de 
ambas puertas: antes de la apertura de la calle Labrador y de la instalación del convento de la Merced, en el entorno de la puerta Nueva, y antes de la apertura de la "nueva calle", en el entorno de la puerta del Agua.

\section{ÍNDICE DE IMÁGENES}

Fig. 1a. Detalle del Plano Topográfico de la Villa de Osuna y sus alrededores de 1826, escala aproximada 1:4.950 (https://bibliotecadigital.rah.es/ es/consulta/registro.do?id=61334)

Fig. 1b. Plano parcial de población del Instituto Geográfico y Estadístico de 1896, a escala 1:2.000 (https://centrodedescargas.cnig.es/ CentroDescargas/)

Fig. 2. Plano base del análisis. Elaboración propia.

Fig. 3. Análisis del recorrido norte. Elaboración propia.

Fig. 4. Joris Hoefnagel. Grabado de Osuna incluido en el $4^{\circ}$ tomo del Civitates orbis terrarum, primera edición de 1588 (http://bdh.bne.es/bnesearch/ detalle/3775533)

Fig. 5. Análisis del recorrido oeste. Elaboración propia. Fig. 6. Detalle del plano actual de catastro para el mismo sector (https://www1.sedecatastro.gob.es/ cartografia/mapa.aspx)

Fig. 7. Análisis del recorrido noroeste. Elaboración propia.

Fig. 8. Detalle del entorno del espacio de la plaza Nueva en los planos de 1896 y de 1974 con superposición del espacio que esta ocupa en el plano de 1826.

Fig. 9. Síntesis de conjunto. Elaboración propia.

\section{BIBLIOGRAFÍA}

DÍAZ, Mercedes (2017): "Evolución de la forma urbana de Carmona. El análisis del plano en el estudio histórico de la ciudad", Arqueología y territorio medieval, 24, pp. 229-254. Universidad de Jaén. Versión electrónica: https://doi.org/10.17561/aytm.v24i0.8
DÍAZ. Mercedes (en prensa): "Arquitectura y ciudad en Osuna en torno al señorío de los condes de Ureña" en Antonio Ampliato y Juan Clemente Rodríguez (coords.), Diego de Riaño, Diego de Siloé y la arquitectura en la transición al Renacimiento. Universidad de Sevilla.

FAJARDO, Antonio (2016): "Una primicia cartográfica. Los planos manuscritos de las principales ciudades de la intendencia de Sevilla mandados levantar por el asistente Arjona, 1825-27", Cuadernos de los Amigos de los Museos de Osuna, ISSN 1697-1019, 18, pp. 37-44. Versión electrónica: https://dialnet.unirioja.es/servlet/ articulo? codigo $=6306424$

LEDESMA, Francisco (2000): "La vida en la calle. Notas sobre la religiosidad, fiestas y teatro en Osuna (siglos XVI-XVIII). II. La procesión del Corpus", Apuntes 2: Apuntes y Documentos para una Historia de Osuna, 3, pp. 193-232. Ayuntamiento de Osuna.

LEDESMA, Francisco (2003): Las murallas de Osuna. Osuna: Fundación El Monte.

LUQUE-ROMERO, Francisco y COBOS, José (2016): "Un modelo de sociabilidad decimonónica. El casino de Osuna desde una perspectiva etnohistórica", Cuadernos de los Amigos de los Museos de Osuna, 18, pp. 167-172. Osuna. Versión electrónica: https://dialnet. unirioja.es/servlet/articulo?codigo $=6306445$

RANGEL, Miguel (2005): "Rehabilitación del teatro Hermanos Álvarez Quintero de Osuna", Cuadernos de los Amigos de los Museos de Osuna, 7, pp. 30-35. Osuna. Versión electrónica: https://dialnet. unirioja.es/servlet/articulo?codigo=2884439

RUIZ, José Ildefonso (2001): "Seguimiento arqueológico en Cuesta de los Cipreses, Osuna (Sevilla), 1998/99”, Anuario arqueológico de Andalucía 1998, Vol. 3, Tomo 2, Actividades de urgencia, pp. 10621074. Sevilla: Consejería de Cultura. Junta de Andalucía.

RUIZ, José IIdefonso (2005): "Control arqueológico en la plataforma exterior de la Universidad de Osuna (Sevilla)", Anuario arqueológico de Andalucía 2002, Vol. 3, Tomo 2, Actividades de urgencia, pp. 546-560. Sevilla: Consejería de Cultura. Junta de Andalucía.

SALAS, Jesús de la Ascensión y PÉREZ, Juan Antonio (1990): "Intervención Arqueológica de Urgencia en la Torre del Agua (Osuna, Sevilla)", Anuario Arqueológico de Andalucía 1988, Tomo 3, pp. 386-391. Sevilla: Consejería de Cultura. Junta de Andalucía. Versión electrónica: https://www.juntadeandalucia.es/export/ drupalida/1988_URGENCIAS_web.pdf

VARGAS, Juan Manuel y ROMO, Ana Salud (2005): "El monasterio de la Encarnación de Osuna (Sevilla). Análisis arqueológico de los paramentos septentrionales", Anuario arqueológico de Andalucía 2002, Vol. 3, Tomo 2, (Actividades de urgencia), pp. 525-533. Junta de Andalucía, Consejería de Cultura. 